\title{
An Empirical Investigation of Faculty Members' Organizational Commitment in the Kingdom of Saudi Arabia
}

\author{
Maha B. BinBakr*, Eman I. Ahmed \\ College of Arts, University of Dammam, Dammam, Saudi Arabia \\ *Corresponding author: mbakr@uod.edu.sa
}

Received July 05, 2015; Revised July 25, 2015; Accepted July 28, 2015

\begin{abstract}
The present study utilizes the Meyer and Allen three-component model of organizational commitment to measure commitment among faculty members in Saudi Arabia. The study further investigates the relationship between the faculty's demographic variables (gender, academic rank, college cluster, years of experience, and nationality) and their organizational commitment. A survey research design was used to measure 185 faculty members' commitment to their organizations. This study's results demonstrate high levels of effective organizational commitment among respondents. Academic rank was found to be significantly related to organizational commitment among other demographic variables. The implications of the study could be used to improve organizational commitment among faculty members in Saudi Arabia.
\end{abstract}

Keywords: organizational commitment, faculty members, saudi arabia, university of dammam

Cite This Article: Maha B. BinBakr, and Eman I. Ahmed, "An Empirical Investigation of Faculty Members' Organizational Commitment in the Kingdom of Saudi Arabia.” American Journal of Educational Research, vol. 3, no. 8 (2015): 1020-1026. doi: 10.12691/education-3-8-12.

\section{Introduction}

Faced with competitive pressures, higher education institutions have paid greater attention to developing a spirit of organizational commitment among their members. According to a previous study [10], an organization's success does not depend only on how it develops employees' competencies but also on how it develops commitment toward the organization.

Organizational commitment has been shown to be one of the most important indicators and factors for success in higher education institutions [11,16]. It is also one of the key factors for organizational survival and effectiveness [24]. A review of the literature reveals that organizational commitment is positively associated with job satisfaction, employee retention, superior work quality, higher productivity, lower turnover rate, and achievement of organizational goals [6].

Consequently, organizational commitment has received extensive conceptual and practical attention in the management literature over the last four decades. According to a reference [15], organizational commitment is a universal topic and is not limited to national boundaries or a particular organization. To promote and systemize organizational functioning for achieving their goals, mission, and objectives, the demographic factors of the employees should be considered by the managers of the organizations [17]. Many investigations have proven that demographic factors could affect organizational commitment and should therefore be controlled.

Empirical studies pertaining to organizational commitment have shown that demographic variables, such as gender, academic rank, and nationality, are among the most frequent variables that affect organizational commitment. Moreover, studies have shown that an employee's perception is an important factor for organizational commitment. Although organizational commitment has been a focus of numerous studies in the last four decades, empirical assessment of faculty commitment in Saudi Arabian universities has been less extensive.

This study is significant as it provides insight into the nature of organizational commitment among faculty members in Saudi universities. The study further investigates the relationship between the faculty member's demographic factors and his or her organizational commitment.

First, as a theoretical explanation of organizational commitment models, the proposed linkages between organizational commitment and demographic variables are described. Next, the methods used in the study and the results are explained. Finally, the implications of the results are presented.

\section{Conceptual Framework}

Early perspectives of organizational commitment have examined the behavioral perspective of commitment. These studies have identified commitment in terms of 
employee behavior and tendency to engage in consistent lines of activity $[2,3,8,23]$. In behavioral organizational commitment, employees are "viewed as committed to particular organizational behaviors rather than to an entity" [24].

Recent perspectives of organizational commitment have focused on attitudinal perspectives of commitment $[5,7,9,15,28,29,31,40]$. In contrast to behavioral commitment, which is concerned with the process by which employees become committed to their own past behaviors, attitudinal commitment focuses on the employee's relationship with the organization [35]. This approach identifies commitment as the employee's identification and acceptance of the organization's goals and values and willingness to exert effort on behalf of the organization to maintain membership in the organization. O'Reilly and Chatman have focused on the attitudinal perspectives of commitment. They classified commitment into three levels: accordance, identification, and internationalization.

Allen and Meyer's model also focused on the attitudinal perspectives of organizational commitment. It defined commitment as the "psychological relation between employees and organization" [28,29]. This model proposes that organizational commitment is experienced by the employee as three simultaneous mindsets encompassing affective, normative, and continuance organizational commitment [22]. Affective commitment is defined as the employee's emotional attachment and level of involvement in the organization [5]. Employees with affective commitment "undertake actions because they want to" [24]. Thus, it is closely related to identification [33]. Continuous commitment is the employee's willingness to stay in the organization to avoid cost of leaving the organization, such as reduction in pay, benefits, or facilities. Employees who have a strong continuous commitment remain in the organization because they need to remain there. Normative commitment is associated with the employee's feeling of moral obligation to the organization [4,9]. Employees believe that the organization is supporting them and they are "obligated to stay with the organization”. Organizational commitment is an "inner psychological feeling that obliged the employee to stay in the organization [33]. Normative commitment is usually the least understood approach in the organizational commitment literature [29].

The present study utilizes the classic 1991 Meyer and Allen three-component model of organizational commitment to understand commitment among faculty members in Saudi universities. This model has been designed as a comprehensive model to understand commitment within the organization. It is one of the dominant models for study of workplace commitment and reflects the multidimensional nature of the construct of commitment [22]. It integrates a variety of alternative conceptualizations and reconciles the opposing ideas in the literature on organizational commitment [35]. Further, it is a powerful model to match organizational commitment components to the employees. Allen and Meyer have stated that employees can experience more than one form of commitment at the same time. They have suggested that each employee has a "commitment profile reflecting the three-component of commitment.
A review of literature on the relationship between organizational commitment and the demographic variables (gender, academic rank, years of experience, and nationality) of faculty members in higher education institutions shows that this issue is still unresolved [1]. Some studies, for example, have studied the relationship between job rank and organizational commitment. The results proved contradictory. On one hand, some studies have found that academic rank had a positive impact on faculty commitment in Kingdom of Saudi Arabia (KSA) universities $[1,21,27,28,36]$. On the other hand, others have found that academic rank was negatively associated with organizational commitment [18,20,33,38].

In addition, other studies have investigated the relationship between gender and organizational commitment. The results also reflect contradictory evidence. Some studies have reported that gender was one of the most important predictors of organizational commitment $[4,13,26]$. Other studies, on the contrary, have reported no significant differences between gender in organizational commitment [33,39].

Some other investigations have been run to examine the relationship between years of experience and organizational commitment. Some studies reported that the years of experience was a highly significant predictor of faculty commitment in KSA universities [21,34]; others found insignificant correlation between years of experience and organizational commitment [1].

Very few studies have examined the relationship between the faculty member's nationality and organizational commitment (OC). Most of these investigations have been explored in the United Arab Emirates [25,37], and have found that nationality of employees was positively and significantly correlated with the level of their commitment. Few studies have examined the relationship between the faculty's nationality and OC, despite the thousands of expatriate faculty employed in KSA universities.

The present study adopted the Meyer and Allen threecomponent model of organizational commitment to understand organizational commitment among faculty in Saudi universities, and investigated the relationship between the faculty member's demographic variables (gender, academic rank, years of experience, and nationality) and organizational commitment (OC).

\section{Research Questions}

This study addressed the following research questions:

RQ1: What is the level of faculty member's affective, normative, continuance and overall organizational commitment?

RQ2: Are there significant differences in faculty member's perception toward overall organizational commitment based on college cluster?

RQ3: Are there significant differences in faculty member's perception toward overall organizational commitment based on academic rank?

RQ4: Are there significant differences in faculty member's perception toward overall organizational commitment based on duration of service in the university? 
RQ5: Are there significant differences in faculty member's perception toward overall organizational commitment based on gender?

RQ6: Are there significant differences in faculty member's perception toward overall organizational commitment based on nationality?

\section{Methodology}

A survey research design was used to address the purpose of the study and understand the research problem better. A fully structured organizational commitment Questionnaire (OCQ) based on the classic 1991 Meyer and Allen three-component model of organizational commitment was developed by the researchers. This questionnaire measures three forms of organizational commitment. It consists of two sections. The first section of the questionnaire solicits information concerning the demographic and the professional characteristics of the participants. The second section consists of 23 items with a five-point response scale that is subdivided into three dimensions. The respondents were asked to examine their perceptions of their organizational commitment. The questionnaire was anonymously and randomly dispatched via internal electronic mail to the participants.

The research sample consisted of a population of fulltime faculty members employed at the University of Dammam, the biggest University in the eastern Province of Saudi Arabia. The sample size was calculated to be 185 ,

$$
n=\frac{\sigma^{2} Z^{2}}{E^{2}}=\frac{1.96^{2} \times 0.25}{0.072^{2}}=185
$$

with a marginal error of 0.072 at the $95 \%$ confidence level.

As the surveys administered in this study used Likerttype scales, Cronbach's alpha $(\alpha)$ was a good indicator of the internal consistency of the survey questions [12]. Whereas Cronbach's alpha is also suitable for providing a reliability coefficient on a homogenous section of an instrument, Pearson Correlation was also a reasonable indicator of the validity of the instrument [12]. The alpha coefficients and the Pearson Correlation for the survey questions were calculated using SPSS and are presented in Table 1 below.

Table 1. Cronbach's Alpha and Pearson Correlation of the OCQ

\begin{tabular}{|c|c|c|c|}
\hline Dimensions & Number of statements & Cronbach's Alpha & Pearson Analysis \\
\hline Affective Commitment & 8 & 0.85 & 0.90 \\
\hline Continuance Commitment & 7 & 0.83 & 0.89 \\
\hline Normative Commitment & 8 & 0.77 & 0.94 \\
\hline Overall Organizational Commitment & 23 & 0.89 & - \\
\hline
\end{tabular}

The standardized item alphas computed revealed that all survey sections had values over .77, as shown in Table 1 , which is statistically accepted as good reliability. To check the validity of the instrument, Person correlations were calculated between each dimension and its subscale, and positive values and ranges from .94 to .89 were found.

\subsection{Demographic Characteristics of the Participants}

Table 2 summarizes the demographic characteristics of the survey respondents, including attributes such as college cluster, academic rank, gender, nationality, and years of work experience. All are represented by the frequency distribution and percentage. Table 2 indicates the demographic breakdown of the sample data.

In summary, $74.6 \%$ of the respondents were females and $25.4 \%$ were males, $47.5 \%$ were Saudis and $52.5 \%$ were non-Saudis, $5 \%$ were professors, $13.8 \%$ were associate professors, $39.8 \%$ were assistant professors, $16.6 \%$ were lecturers, and $24.9 \%$ were demonstrators. Looking at the duration of service at UoD, $51.4 \%$ of the participants had 5 years or less experience, $18.8 \%$ had between 5 and 10 years experience, and 29.8\% had more than 10 years of experience. By college cluster, 23\% represented the Health Profession path, 5.2\% represented the Engineering path, 32.6\% represented Sciences \& Business Management, and 39.3\% represented Arts \& Education.
Table 2. Demographic Characteristics of the Participants

\begin{tabular}{|c|c|c|}
\hline Variables & Number & $\%$ \\
\hline \multicolumn{3}{|c|}{ College Cluster: } \\
\hline Health Professions Cluster & 53 & 24.3 \\
\hline Engineering Colleges Cluster & 10 & 5.5 \\
\hline Sciences \& Management Cluster & 54 & 24.8 \\
\hline Arts \& Education Cluster & 64 & 35.4 \\
\hline \multicolumn{3}{|c|}{ Academic Rank: } \\
\hline Professor & 9 & 5 \\
\hline Associate professor & 25 & 13.8 \\
\hline Assistant Professor & 72 & 39.8 \\
\hline Lecturer & 30 & 16.6 \\
\hline Demonstrator & 45 & 24.9 \\
\hline \multicolumn{3}{|c|}{ Gender: } \\
\hline Male & 46 & 25.4 \\
\hline Female & 135 & 74.6 \\
\hline \multicolumn{3}{|c|}{ Nationality: } \\
\hline Saudi & 86 & 47.5 \\
\hline Non Saudi & 95 & 52.5 \\
\hline \multicolumn{3}{|c|}{ Duration of service at UoD: } \\
\hline 5 yrs or less & 93 & 51.4 \\
\hline$>5-10$ & 34 & 18.8 \\
\hline$>10$ yrs & 54 & 29.8 \\
\hline TOTAL & 181 & 100 \\
\hline
\end{tabular}




\section{Results and Analysis}

To measure the organizational commitment (OC) among the respondents, the data obtained were analyzed using SPSS. Data analysis consisted of descriptive analyses, frequency distributions, t-tests, and one-way
ANOVAs. T-test and one-way ANOVA results were used to measure the significant differences between the means of college cluster, academic ranking, duration of service in the university, gender and nationality among the participants for the overall organizational commitment.

\begin{tabular}{|c|c|c|c|c|c|c|c|}
\hline \multirow{2}{*}{ Descriptive Statistics } & \multirow{2}{*}{$\mathrm{N}$} & \multirow{2}{*}{ Mean } & \multirow{2}{*}{ St D } & \multirow{2}{*}{ Levels } & \multicolumn{3}{|c|}{ Frequency (\%) } \\
\hline & & & & & High & Mode-rate & Low \\
\hline Affective Commitment & 176 & 4.15 & 0.59 & $\mathrm{H}$ & $\begin{array}{c}149 \\
(84.7 \%)\end{array}$ & $\begin{array}{c}26 \\
(14.8 \%)\end{array}$ & $\begin{array}{c}1 \\
(0.6 \%)\end{array}$ \\
\hline Continuance Commitment & 173 & 3.65 & 0.75 & M & $\begin{array}{c}90 \\
(52.0 \%)\end{array}$ & $\begin{array}{c}72 \\
(41.6 \%)\end{array}$ & $\begin{array}{c}11 \\
(6.4 \%)\end{array}$ \\
\hline Normative Commitment & 175 & 4.01 & 0.56 & $\mathrm{H}$ & $\begin{array}{c}127 \\
(72.6 \%)\end{array}$ & $\begin{array}{c}47 \\
(26.9 \%)\end{array}$ & $\begin{array}{c}1 \\
(0.6 \%)\end{array}$ \\
\hline Overall OC & 173 & 3.94 & 0.58 & $\mathrm{H}$ & $\begin{array}{c}127 \\
(73.4 \%)\end{array}$ & $\begin{array}{c}45 \\
(26.0 \%)\end{array}$ & $\begin{array}{c}1 \\
(0.6 \%)\end{array}$ \\
\hline
\end{tabular}

Note: L=Low (1-2.33). M=Moderate (2.34- 3.66), H=High (3.67-5).

\subsection{Research Question 1: Level of Affective, Continuance, Normative and Overall Organizational Commitment}

Table 3 shows that a high level of commitment was reported for affective, normative and overall OC with $(\mathrm{M}=4.15$ and $\mathrm{SD}=.59), \quad(\mathrm{M}=4.01$ and $\mathrm{SD}=.56)$, and $(\mathrm{M}=3.94$ and $\mathrm{SD}=.58)$, respectively. Affective commitment was higher than continuance and normative commitment and overall OC. The majority of the respondents (84.7\%) rated they had a high level of affective commitment, $14.8 \%$ rated that they had a moderate level of commitment, and less than $1 \%$ rated that they had a low level of commitment. One hundred twenty seven of the respondents (72.6\%) and 47 of the respondents (26.9\%) reported high and moderate normative commitment, respectively. A moderate level of commitment was reported for continuance commitment $(\mathrm{M}=3.65, \mathrm{SD}=.75)$. More than half $(52.0 \%)$ of the respondents had a high level of commitment, $41.6 \%$ had a moderate level of commitment, and $6.4 \%$ reported a low level of commitment for continuance commitment. One hundred twenty seven respondents $(73.4 \%)$ rated a high level of commitment, and $26.0 \%$ rated a moderate level of commitment for overall OC. Findings in Appendix 1 illustrate the descriptive statistics for all OC statements arranged in descending order. The respondents possessed a high level of commitment towards the majority of the statements $(16,69.6 \%)$, with a mean ranging from 4.50 to 3.74 and St D ranging from 28.87 to 14.89 . The respondents also had a moderate level of commitment (30.4\%) with a mean ranging from 3.58 to 3.19 and St D ranging from 36.67 to 29.05 .

\subsection{Research Questions 2, 3, 4: Are There Significant Differences in the Faculty Member's Perception of Overall Organizational Commitment Based on College Cluster, Academic Rank, and DURATION of Service at UoD?}

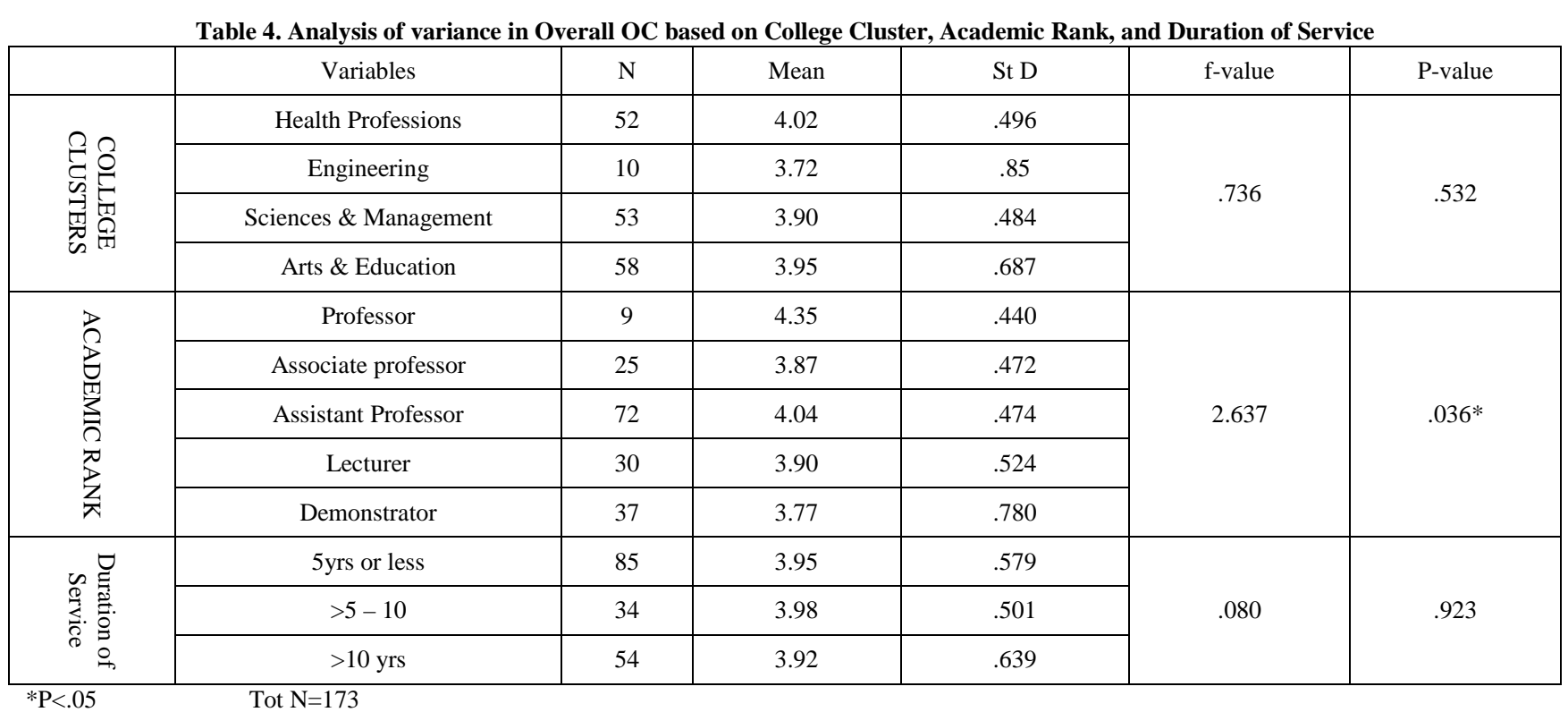

Table 4 shows that significant differences existed for overall commitment among the respondents based on academic rank, $(\mathrm{F}=2.637, \mathrm{p}<0.05)$. However, there were no significant differences among the respondents based on college cluster $(\mathrm{F}=.735, \mathrm{p}>0.05)$. Likewise, the one -way ANOVA showed no significant differences among the participants based on duration of services at UoD (F $=.080, \mathrm{p}^{>} 0.05$ ). 
5.3. Research Questions 5 and 6: Are There Significant Differences in the Faculty Member's Perception of Overall Organizational Commitment Based on Gender and Nationality?

Table 5. T-Test analysis for overall OC based on Gender and Nationality

\begin{tabular}{|c|c|c|c|c|c|c|}
\hline \multirow{2}{*}{ GENDER } & Female & 129 & 3.93 & .532 & \multirow{2}{*}{.320} & .75 \\
\cline { 2 - 6 } & Male & 44 & 3.97 & .730 & & \\
\hline \multirow{2}{*}{ NATIONALITY } & Saudi & 93 & 3.89 & .497 & \multirow{2}{*}{-1.127} & \multirow{2}{*}{.261} \\
\cline { 2 - 6 } & Non- Saudi & 80 & 3.99 & .650 & & \\
\hline \multirow{2}{*}{$* \mathrm{p}<.05$} & \multicolumn{2}{|c|}{ Tot N=173. } & & \\
\end{tabular}

The results of the t-tests in Table 5 show that there were no significant differences between male and female faculty members for overall organizational commitment $(\mathrm{t}$ $=0.320, \mathrm{p}>0.05)$. Likewise, the t-test indicated that there were no significant differences between Saudi and NonSaudi faculty members on overall organizational commitment $(\mathrm{t}=-1.127$ and $\mathrm{p}>0.05)$.

\section{Discussion}

Although organizational commitment is crucial to the success of higher education institutions, few studies have focused on commitment in higher education institutions in Saudi Arabia [14,19]. Moreover, the investigations that have been performed over the past years reveal that the relationship between organizational commitment and the demographic variables of the faculty members in higher education institutions is still unresolved [1]. This study was designed to examine the level of organizational commitment among faculty members in Saudi Arabia. The study further investigated the relationship between the faculty member's demographic variables (gender, academic rank, college cluster, years of experience, and nationality) and their organizational commitment.

To measure the commitment among the faculty members in Saudi Arabia, the researchers used the classic 1991 Meyer and Allen three-component model of organizational commitment. The three component model is still not well investigated in other cultures besides Western, English-speaking countries.

The research sample consisted of a population of fulltime faculty employed in one of the leading universities in Saudi Arabia. An exploratory investigation was used to better address the purpose of the study and to understand the research problem. The analysis of the data showed that the faculty had a moderate level of commitment. The results also reflected that the faculty members had a high level of affective commitment and were emotionally attached to the university and that the university had a great deal of personal meaning for faculty; they did feel "obliged or trapped". This finding is consistent with the previous research findings [1,30,33].

Among the demographic variables used in this study, only academic rank was found to be significantly related to the faculty member's organizational commitment. The higher the academic rank was, the more the faculty member was committed to the university. This result is in line with that of other studies [28,32,33,36].

No significant difference was found between duration of service in the university and overall organizational commitment. This result is also in line with that of Alshitri [1]. Most of the respondents (51.4\%) had 5yrs or less of service at the university. This may help to explain why no significant differences were found between the faculty members' duration of service in the university and overall organizational commitment.

The results also indicated that no significant differences existed between Saudi and non-Saudi faculty on overall organizational commitment $(\mathrm{t}=-1.127, \mathrm{p}>0.05)$. The faculty distribution by nationality that were exhibited on the university website shows that $75 \%$ of non-Saudi faculty come from Arab countries in the region with challenging working life conditions and benefits (Yemen, Sudan, Syria, Egypt, Tunisia, and Jordan). This may help to explain the high organizational commitment among the non-Saudi faculty members.

The analysis of the data also showed that no significant differences existed between male and female faculty in their level of organizational commitment. This finding is consistent with that of Zaitouni, et al., and Nazari, et al., $[33,39]$. In Saudi higher education institutions, no gender bias is observed. Moreover, work benefits and financial compensation in Saudi universities are equally distributed between male and female faculty, and this may contribute to the overall male and female faculty commitment. This may help to explain why no significant differences were found between male and female faculty on overall organizational commitment.

\section{Conclusions}

The study reports an empirical investigation of organizational commitment among faculty members in Saudi Arabia. Organizational commitment has been proven to have a significant positive effect on the overall teaching performance of faculty members, and could be an important indicator of organizational efficiency and effectiveness [24]. This study is significant as it develops understanding and awareness of the nature of organizational commitment among faculty members of different cultures. It also provides new investigation and data about the relationship between organizational commitment and demographic variables in higher education institutions in Saudi Arabia. However, the results of the study were based only on data from University of Dammam. Therefore, the results represented only the faculty members at this institution and could not be generalized to all faculty members in Saudi Arabia. Further investigations are needed to examine faculty member's organizational commitment at other universities.

\section{Implications for Practice}

The present study recommends that University administration take into consideration the needs and expectation of all faculty members to help improve their organizational commitment, especially in areas addressing their training \& development, their work conditions, their 
financial compensation, and their other work benefits. Moreover, policymakers should develop policies that encourage and support organizational commitment among faculty members in Saudi Arabia.

Further studies to investigate the effect of organizational efficiency and effectiveness to faculty members' OC, and investigations of some independent variable such as job involvement, job satisfaction, and turnover intention among faculty, is recommended.

In general, further empirical assessment of the Meyer and Allen three-component model of organizational commitment would add to knowledge of organizational commitment among employees in other universities and other types of organizations and to the scientific credibility of this model.

\section{Acknowledgments}

The authors thank the deanship of Information and Communication Technology at the University of Dammam for assessing the electronically distributed OCQ. Further thanks are due to all chairpersons of the departments in all of the colleges for their help in data collection and in related logistics pertaining to the present study. Special thanks go to all faculty members who readily completed and returned the questionnaires.

\section{References}

[1] Alshitri, K, "The effects of the personal variables on organizational commitment in public organizations in Saudi Arabia,” IBIMA Business Review, Article ID 725189, 2013.

[2] Aluto, J., Herbiniak, L. and Alonso, R, “ On operationalizing the concept of commitment,” Social Forces, 51(4), 448-454, 1973.

[3] Angel, H. and Perry, J, "Organizational commitment: Individual and Organizational Influence,” Work and Occupation, 10(2), 123146, 1983.

[4] Aydin, A., Sarier, Y. and Uysal, S, "The Effect of Gender on Organizational Commitment of Teachers: A Meta Analytic Analysis,” Educational Sciences: Theory \& Practice, 11(2), 628632, 2011.

[5] Aydin, A., Sarier, Y. and Uysal, S, "The effect of school principals' leadership styles on teachers' organizational commitment and job satisfaction,” Educational Sciences: Theory and Practice, 13(2), 806-811, 2013.

[6] Azeem, S . and Akhtar, N, "Job Satisfaction and organizational commitment among public sector employees in Saudi Arabia," International Journal of Business and Social Science, 5(7), 127133, 2014.

[7] Balay, R, "Effect of learning organization perception to the organizational commitment: A comparison between private and public university," Educational Sciences: Theory and Practice, 12(4), 2474-2486, 2012.

[8] Becker, H, "Notes on the concepts of commitment," American Journal of Sociology, 66(1), 32-40, 1960.

[9] Bergami, M. and Bagozzi, R, "Self- Categorization, affective commitment, and group self-esteem as distinct aspects of social identity in the organization,” British Journal of Social Psychology, 39(1), 555-577, 2000.

[10] Beukhof, G., De Jong, M. J. and Nijhof, W. J, "Employee Commitment in Changing Organization: An Exploration,” Journal of European Industrial Training, Vol. 22, No. 6, 243-248, 1998.

[11] Bhatnagar, J, "Predictors of organizational commitment in India: strategic HR roles, organizational learning capability and psychological empowerment,” Human Resource Management, 18(10), 1782-1811, 2007.

[12] Black, R., Doing Quantitative Research in the Social Sciences. London: Sage, 1999.
[13] Boon, O. K. et al., "TQM Practices and Affective Commitment: A Case of Malaysian Semiconductor Packaging Organizations," International Journal of Management and Entrepreneurship, 2(1), 37-55, 2006.

[14] Chughtai,. A. and Zafar, S, “Antecedents and Consequences of Organizational Commitment Among Pakistani University Teachers,” Applied Human Research Management, 11(1), 39-64, 2006.

[15] Cohen, A, "Commitment before and after: An evaluation and reconceptualization of organizational commitment," Human Resource Management Review, 17(3), 336-354, 2007.

[16] Davoodipoor, A., Ahancheyan, M.. and Rezvani, M. S, "The implementation of management schoolbased plan according to mission, cooperation and organizational commitment among administrators and teachers of guidance schools in Mashad city in Iran,” The new Thoughts in Educational Sciences 4, 37-53, 2008.

[17] Giffords, E, “An Examination of Organizational Commitment and Professional Commitment and the Relationship to Work Environment Demographic and Organizational Factors,” Journal of Social Work, 9(4), 386-404, 2009.

[18] Glisson, C . and Durick, M, "Predictors of Job satisfaction and organizational commitment in human service organizations, “Administrative Science Quarterly, 33, 61-81, 1988.

[19] Hossaini, S., Amirtash, M. and Mozafari, A,” Relationship, comparison and explanation of different leadership styles with organizational commitment among scientific boards of lecturers in Iran universities," Sport Sciences and Moving, 1(6), 83-94, 2005.

[20] Iqbal A,"An Empirical Assessment of Demographic Factors, Organizational Ranks and Organizational commitment”, International Journal of Business and Management, 5, (3), 16-27, 2010.

[21] Iqpal, A., Kokash, H. and Al-Oun, S, "The impact assessment of demographic factors on faculty commitment in the Kingdom of Saudi Arabian Universities," Journal of College Teaching\& Learning, 8(2), 1-13, 2011.

[22] Jaros, S, "Meyer and Allen model of organizational commitment: Measurement issues,"The ICFAI Journal of Organizational Behavior, VI (4), 7-25, 2007.

[23] Kanter, R, “Commitment and social organization: A study of commitment mechanisms in the utopian communities," American Journal of Sociology, 33, 499-517, 1986.

[24] Krishna, V. and Marquardt, M, "A Framework for the development of organizational using action learning," Avaliable: http://files.eric.ed.gov/fulltext/ED504566.pdf. [Accesses April 2, 2015].

[25] Lim, C, What's in it for me? Organizational commitment among faculty members in UAE business schools. Finland: Universitatis Ouluensis, 2014.

[26] Lim, T, "Relationships among organizational commitment, job satisfaction, and learning organization culture in one Korean private organization,” Asia Pacific Education Review, 11(3), 311320, September 2010.

[27] Mathieu, J. E. and Zajac, D. M, (“A review and meta-analysis of the antecedents, correlates, and consequences of organizational commitment,” Psychological Bulletin, 108(2), 171-194, 1990.

[28] Meyer, J. and Allen, N, “A ThreeComponent Conceptualization of Organizational Commitment”, Human Resource Management Review 1(1), 61-89, 1991.

[29] Meyer, J., \& Allen, N. (1997). Commitment in the workplace: Theory, research, and application, Thousand Oaks, CA: SAGE Publications.

[30] Meyer, J. and Stanely, "Affective, Normative, and continuance commitment levels across cultures: A meta- analysis,” Journal of Vocational Behavior, 80, 225-245, 2012.

[31] Mowday, R., et al,. “The measurement of organizational commitment,” Journal of Vocational Behavior, 224-247, 1979.

[32] Nancy, F., Factors Predicting faculty commitment to the university, in the 33th Annual Forum of the Association for Institutional Research, Chicago: IL,2001.

[33] Nazari, K, et.al, “An empirical investigation of lecturers' organizational commitment in technical and vocational colleges in Iran,” International Refereed Journal, III (1), 1-10, 2012.

[34] Salami, S. O, "Demographic and Psychological Factors Predicting Organizational Commitment among Industrial Workers," Anthropologist,. 10( 1), 31- 38, 2008.

[35] Sersic, D, “An empirical test of Meyer and Allen' s threecomponent model of organizational commitment in Croatian context,” Review of Psychology, 6(1-2), 17-24, 1999. 
[36] Steers, R, "Antecedents and outcomes of organizational commitment,” Administrative Science Quarterly, 22(1), 46-56, 1977.

[37] Yaghi, A, "Examining organizational commitment among national and expatriate employees in the private and public sectors in United Arab Emirates,” International Journal of Public Administration, 37(4), 2014.

[38] Yew, L, "Job Satisfaction and Affective Commitment: A Study of Employees in the Tourism Industry in Sarawak, Malaysia,” World
Review of Entrepreneurship, Management and Sustainable Development, 4(1), 85-101, 2008.

[39] Zaitouni, M., et al., "The Impact of Human Resource Management Practices on Organizational Commitment in the Banking Sector in Kuwait,” International Journal of Business and Management, 6(5), 108-123, 2011.

[40] Zanagro, G, "Oragizational commitment: A concept analysis," Nursing Forum, 36(2), 1-14, 2001.

\section{APPENDIX 1}

\section{Organizational Commitment Statements}

\begin{tabular}{|c|c|c|c|c|c|}
\hline Statement & Type & $\mathrm{N}$ & Mean & Level & St D \\
\hline $\begin{array}{l}\text { I am rarely absent from my work since I have a moral obligation } \\
\text { with my organization }\end{array}$ & $\mathrm{N}$ & 171 & 4.50 & High & .87 \\
\hline $\begin{array}{l}\text { I do more than what the task defines because I am loyal to my } \\
\text { organization. }\end{array}$ & $\mathrm{N}$ & 172 & 4.43 & High & 66 \\
\hline $\begin{array}{l}\text { I am working in this organization out of necessity as much as } \\
\text { desire. }\end{array}$ & $\mathrm{C}$ & 171 & 4.31 & High & .78 \\
\hline I really feel as if the organization's success as my own. & A & 170 & 4.30 & High & .84 \\
\hline I am very happy to continue working for this organization. & A & 171 & 4.28 & High & 69 \\
\hline $\begin{array}{l}\text { I believe one must always dedicate his/ her knowledge and } \\
\text { experience to the organization. }\end{array}$ & $\mathrm{N}$ & 171 & 4.27 & High & .77 \\
\hline $\begin{array}{l}\text { I believe a person must remain loyal to his or her organization } \\
\text { and care to maintain relations with other members of the } \\
\text { organization. }\end{array}$ & $\mathrm{N}$ & 170 & 4.25 & High & .76 \\
\hline $\begin{array}{l}\text { I am happy to exert my effort to achieve my organization's goals } \\
\text { and values. }\end{array}$ & A & 173 & 4.23 & High & .72 \\
\hline $\begin{array}{l}\text { I would be very happy to do things even if there is no clear } \\
\text { reward or punishment. }\end{array}$ & A & 172 & 4.23 & High & .82 \\
\hline I have a strong sense of belonging to my organization. & A & 172 & 4.15 & High & .81 \\
\hline I really feel that my organization makes me feel important. & A & 171 & 4.09 & High & .94 \\
\hline $\begin{array}{l}\text { I believe one must always be loyal to the organization's norms } \\
\text { and values. }\end{array}$ & $\mathrm{N}$ & 172 & 4.09 & High & .79 \\
\hline My organization brings me personal fulfillment and satisfaction. & A & 170 & 4.06 & High & .86 \\
\hline $\begin{array}{l}\text { I continue working in the organization because I do not have } \\
\text { other options. }\end{array}$ & $\mathrm{C}$ & 171 & 4.02 & High & 1.02 \\
\hline I am emotionally attached to this organization. & A & 172 & 3.94 & High & 1.03 \\
\hline $\begin{array}{l}\text { It would be very hard for me to leave my organization because it } \\
\text { satisfies my needs. }\end{array}$ & $\mathrm{C}$ & 171 & 3.74 & High & 1.08 \\
\hline $\begin{array}{l}\text { I am worried if I move to another organization I may scarify the } \\
\text { compatibility of my current work stress level to my } \\
\text { responsibilities. }\end{array}$ & $\mathrm{C}$ & 168 & 3.58 & Moderate & 1.04 \\
\hline My organization deserves my loyalty. & $\mathrm{N}$ & 169 & 3.50 & Moderate & 1.08 \\
\hline $\begin{array}{l}\text { I feel I owe my organization for with the professional training } \\
\text { and development programs it provides. }\end{array}$ & $\mathrm{N}$ & 172 & 3.50 & Moderate & 1.19 \\
\hline $\begin{array}{l}\text { I have a moral sense of obligation to remain in the organization } \\
\text { for all the collaborative learning opportunities and resources it } \\
\text { gave me. }\end{array}$ & $\mathrm{N}$ & 172 & 3.48 & Moderate & 1.05 \\
\hline My life may be disturbed if I decided to leave my organization. & $\mathrm{C}$ & 172 & 3.38 & Moderate & 1.19 \\
\hline $\begin{array}{l}\text { My organization shows consideration to my financial needs } \\
\text { which may not be matched by other organizations if I leave. }\end{array}$ & C & 171 & 3.31 & Moderate & 1.14 \\
\hline $\begin{array}{l}\text { I will not leave this organization because I am satisfied with my } \\
\text { salary. }\end{array}$ & $\mathrm{C}$ & 171 & 3.19 & Moderate & 1.17 \\
\hline
\end{tabular}

Note: Low (1-2.33), Moderate (2.34- 3.66), High(3.67-5)

Note: (A=Affective Commitment), ( $\mathrm{C}=$ Continuance Commitment), (N=Normative Commitment). 